\title{
Condenação de carcaças de bovinos acometidos por brucelose provenientes das regiões Baixo Amazonas e Sudoeste Paraense
}

\author{
Bovine carcass condemnation for brucellosis from municipalities \\ of Baixo Amazonas and Sudoeste Paraense regions
}

Grecia Aires Roma ${ }^{1}$, Adna Sousa de Lima (D) ${ }^{1}$, Welligton Conceição da Silva (D) 2*, Helder Ribeiro Batista (D)1, Raimundo Nonato Colares Camargo Júnior (iD ${ }^{3}$

\footnotetext{
1 Faculdades Integradas do Tapajós, Universidade da Amazônia (FIT/UNAMA), Santarém, PA, Brasil

2 Universidade Federal Rural da Amazônia (UFRA), Santarém, PA, Brasil

${ }^{3}$ Instituto Federal de Educação, Ciência e Tecnologia do Pará (IFPA), Belém, PA, Brasil
}

\section{Resumo}

A brucelose bovina, enfermidade de distribuição mundial ocasionada principalmente pela Brucella abortus, acarreta prejuízos econômicos e de ordem sanitária. O objetivo deste trabalho foi verificar a prevalência de condenação de carcaças de bovinos abatidos por brucelose no ano de 2018, nas regiões do Baixo Amazonas e Sudoeste Paraense. O estudo foi realizado em três abatedouros frigoríficos, sob inspeção municipal, localizados no município de Santarém, Pará. Foram inspecionados 23.963 bovinos oriundos dos municípios de Placas, Rurópolis, Santarém e Uruará. Os bovinos eram condenados quando apresentavam lesões macroscópicas características de brucelose,

* Autor correspondente: welligton.medvet@gmail.com Submetido: 13 jan 2020 | Aprovado: 07 abr 2020 presentes no interior das carcaças ou em diferentes órgãos. Foram condenados por brucelose 62 bovinos abatidos no ano de 2018. Observou-se maior índice de condenações no primeiro semestre do ano, sendo Santarém o município que apresentou maior quantidade de machos condenados; no entanto, as fêmeas foram predominantes entre os casos de condenações por município. Com relação à idade, identificou-se que $52,4 \%$ (22) dos animais tinham idade superior a 7 anos, $11,9 \%$ (5) tinham entre 3 e 7 anos e 35,7\% (15) abaixo de 3 anos.

Palavras-chave: Pecuária. Vacas. Zoonose. 


\section{Abstract}

Bovine brucellosis, a disease of worldwide distribution caused mainly by Brucella abortus, causes economic and sanitary losses. The objective of this work was to verify the prevalence of condemnation of bovine carcasses slaughtered by brucellosis, in 2018, in the Baixo Amazonas e Sudoeste Paraense regions, Brazil. The study was carried out in three slaughterhouses, under municipal inspection, located in Santarém city, Pará, Brazil. A total of 23,963 bovines were inspected in 2018. Bovines from the cities of Placa, Rurópolis, Santarém and Uruará were evaluated. Bovines were condemned when they had macroscopic lesions characteristic of brucellosis, present inside of the carcasses or in different organs. A total of 62 bovines condemned by brucellosis were slaughtered in 2018. A higher rate of condemnation was observed in the first half of the year, with Santarém being the city with the highest number of condemned males, however females were predominant among cases of condemnation by municipalities. Regarding age, it was identified that $52.4 \%$ (22) of the animals were over 7 years old, 11.9\% (5) were between 3 and 7 years old, and $35.7 \%$ (15) under 3 years old.

Keywords: Livestock. Cows. Zoonosis.

\section{Introdução}

A brucelose é uma zoonose infecciosa de evolução crônica e bacteriana, que atinge os bovinos e manifesta-se principalmente por abortos no fim da gestação (Zinsstag et al., 2015), nascimento de bezerros fracos e natimortos e em orquite nos machos. É causada principalmente pela bactéria denominada Brucella abortus, intracelular facultativa, conhecida vulgarmente como moléstia de Bang. A presença da brucelose em rebanhos brasileiros, tanto de leite como de corte, ainda é alarmante, causando uma série de prejuízos durante a cadeia produtiva (Acha e Szyfres, 2001; Bataier Neto et al., 2009; Poester et al., 2013).

No post-mortem, observa-se a presença de lesões sugestivas de brucelose, como: bursite caracterizada como bolsa serosa, localizada na região da cernelha; higroma, que consiste no edema das articulações; e nódulos no baço, fígado e linfonodos.

Essa enfermidade causa esterilidade temporária ou permanente, repetição de cio e perdas na produção de leite por mastites específicas. A vacinação preventiva é obrigatória em todas as fêmeas bovinas e bubalinas na faixa etária de 3 a 8 meses de idade, de acordo com a Instrução Normativa $n^{\circ} 10$ (Brasil, 2017a). Em propriedades certificadas, as vacinas devem ser aplicadas em bezerras até 6 meses de idade (Lauar, 1983; Poester et al., 2009).

Em decorrência da grande atividade pecuária no Brasil, a brucelose bovina é uma preocupação de saúde pública e animal. Embora as medidas de controle e prevenção tenham sido eficazes e que nos últimos dez anos tenha ocorrido redução do número de focos, a brucelose ainda se encontra presente em vários estados do país (Baptista et al., 2012; Celestino et al., 2016; Leal Filho et al., 2016; Oliveira et al., 2016). A principal ferramenta de controle é a prevenção, pois possibilita a erradicação da brucelose, sendo necessárias medidas e ações em todas as esferas públicas, além do incentivo e engajamento da iniciativa privada (Rocha et al., 2009).

O objetivo deste trabalho foi verificar a prevalência de condenação de carcaças por brucelose, de bovinos abatidos no ano de 2018, nas regiões Baixo Amazonas e Sudoeste Paraense.

\section{Material e métodos}

Os dados do estudo foram disponibilizados pela Secretaria Municipal de Agricultura e Pesca (SEMAP), do Departamento de Inspeção Municipal localizado no município de Santarém, Pará, Brasil (02 $26^{\prime} 35^{\prime \prime} \mathrm{S}$ e $54^{\circ} 42^{\prime} 30^{\prime \prime} \mathrm{W}$ ).

Os dados continham informações de condenações de bovinos acometidos por brucelose de três abatedouros frigoríficos sob Serviço de Inspeção Municipal (SIM). Foram considerados, especificamente, sexo, idade, origem, total de animais abatidos e causas de condenação de carcaças por brucelose. O sexo, a idade e o município de origem foram identificados através do Guia de Trânsito Animal (GTA). 
Foram inspecionados 23.963 bovinos no ano de 2018, provenientes das regiões do Baixo Amazonas e Sudoeste Paraense, oriundos, respectivamente, dos municípios de Placas e Santarém, Rurópolis e Uruará. As condenações foram realizadas com base na inspeção das lesões macroscópicas sugestivas de brucelose, presentes no interior das carcaças ou em diferentes órgãos avaliados (linfonodos, articulação, fígado, baço e cernelha), conforme preceitua o Decreto $n^{\circ} 9.013$ (Brasil, 2017b).

Para o cálculo de prevalência, considerou-se o total de condenações por brucelose para os quatro municípios (Placas, Rurópolis, Santarém e Uruará) em comparação ao total de animais abatidos de toda a região sudoeste do Pará.

Para calcular a prevalência por período de condenação de carcaças acometidas por brucelose, utilizou-se a seguinte fórmula, conforme descrita por Elandt-Johnson (1975):

$$
p=\frac{\begin{array}{c}
\text { número de indivíduos afetados em } \\
\text { determinado momento }
\end{array}}{\text { total de indivíduos estudados }}
$$

Após a coleta dos dados, estes foram tabulados e posteriormente organizados em planilhas do programa Microsoft Excel ${ }^{\circledR}$ 2013. Em seguida, foram submetidos à análise estatística descritiva, obtendo média, desvio padrão e variância, sendo expostos dados percentuais.

\section{Resultados e discussão}

Dos 23.963 bovinos abatidos nos três abatedouros (SIM), 148 foram condenados. Destes, 62 apresentavam lesões sugestivas de brucelose, sendo $42(67,7 \%)$ provenientes especificamente de Placas, Rurópolis, Santarém e Uruará. Constatou-se, no ano de 2018, uma prevalência de condenações de carcaças de bovinos por brucelose de 0,001\% (42/23963), ou seja, inferior a $1 \%$. Esse valor pode ser resultado da implementação do Programa Nacional de Controle e Erradicação da Brucelose e Tuberculose Animal (PNCEBT) nas propriedades, minimizando os impactos negativos da enfermidade no rebanho.
Posto isso, a ocorrência da enfermidade no rebanho pode ser explicada, dentre outros fatores, pela falta de monitoramento nas propriedades. Consequentemente, o diagnóstico só ocorre durante a inspeção das carcaças, por ocasião do abate.

Resultados semelhantes foram encontrados por Sabedot et al. (2009), ao relatarem 0,14\% de prevalência de brucelose em bovinos na região sudoeste do Paraná. No estudo realizado por Freitas e Oliveira (2005), a prevalência da brucelose bovina foi de $0,099 \%$, superior à encontrada no presente estudo.

Identificou-se diferença entre os sexos: dos 42 bovinos condenados, $14,3 \%$ eram machos e $85,7 \%$ eram fêmeas, o que pode ser explicado pela maior quantidade de fêmeas enviadas ao abate no ano de 2018 na região estudada. Resultados semelhantes foram encontrados por Freitas et al. (2008) em um estudo onde $82,2 \%$ dos animais positivos eram fêmeas e $18,5 \%$ eram machos. Uma possível explicação para a maior incidência nas fêmeas seria o fato dessas passarem mais tempo no rebanho, favorecendo o aparecimento de manifestações clínico-patológicas detectáveis durante a inspeção post-mortem. A principal porta de entrada da brucelose em bovinos é a digestiva, podendo também dar-se na reprodução, por monta natural, mas sobretudo por inseminação artificial (Monteiro et al., 2006). A entrada do agente nas criações ocorre, principalmente, através de fêmeas infectadas com ou sem histórico anterior de abortamento (Beer, 1988; Poletto et al., 2004). Para a indústria animal, o abate de fêmeas em maior escala pode indicar redução na produção de bezerros.

Com relação à idade, identificou-se que 52,4\% dos animais tinham idade superior a 7 anos, 11,9\% tinham idade entre 3 e 7 anos e 35,7\% abaixo de 3 anos (Tabela 1). Os resultados encontrados corroboram os de Pereira et al. (2009), ao identificarem que o maior número de bovinos positivos possuía idade superior a 7 anos, seguidos pelos animais mais jovens com idade de 0 a 3 anos. De acordo com Sabedot et al. (2009), esses animais jovens podem ter adquirido a enfermidade por meio da ingestão de leite contaminado das fêmeas adultas, disseminando a doença. 
Tabela 1 - Frequência de idade dos bovinos condenados por brucelose em 2018 nas regiões do Baixo Amazonas e Sudoeste Paraense

\begin{tabular}{ccc}
\hline Idade (anos) & Total (n) & $\%$ \\
\hline$<3$ & 15 & 35,7 \\
$3-7$ & 05 & 11,9 \\
$>7$ & 22 & 52,4 \\
\hline
\end{tabular}

Identificou-se maior quantidade de casos de brucelose em animais provenientes do município de Rurópolis, seguido de Uruará, Santarém e Placas. Em relação ao sexo, constatou-se maior número de fêmeas acometidas provenientes de Rurópolis, seguido de Uruará, Santarém e Placas. O município de Santarém apresentou a maior quantidade de machos com a enfermidade em comparação com os demais municípios (12\%), seguido por Uruará com 2,3\%. Os municípios de Rurópolis e Placas não apresentaram casos de condenação em machos (Tabela 2).

Constatou-se que no município de Santarém houve maior incidência de condenações de animais com brucelose nos meses de dezembro e janeiro, e não foram identificados registros nos meses de março, maio, agosto, setembro e novembro. No município de Uruará, observouse maior quantidade de casos no mês de maio, seguido de outubro, fevereiro, janeiro, março e dezembro, não sendo observados casos nos demais meses (Figura 1). Isso pode ser explicado pela ocorrência do período chuvoso, uma vez que o município de Santarém possui área de várzea, onde os animais são criados em sistema extensivo. Assim, quando apresentam bom escore corporal, os animais são realocados à terra firme e posteriormente encaminhados ao abate, entre os meses de janeiro e junho.

Tabela 2 - Frequência de casos de bovinos condenados por brucelose em 2018 de acordo com a cidade e o sexo nas regiões do Baixo Amazonas e Sudoeste Paraense

\begin{tabular}{lccc}
\hline \multirow{2}{*}{ Cidade } & Total de & \multicolumn{2}{c}{ Número de casos (\%) } \\
\cline { 3 - 4 } & casos $(\%)$ & Fêmea & Macho \\
\hline Rurópolis & $13(30,9)$ & $13(30,9)$ & - \\
Uruará & $12(28,6)$ & $11(26,2)$ & $01(2,3)$ \\
Santarém & $11(26,2)$ & $06(14,3)$ & $05(12,0)$ \\
Placas & $06(14,3)$ & $06(14,3)$ & - \\
Total & $42(100)$ & $36(85,7)$ & $06(14,3)$ \\
\hline
\end{tabular}

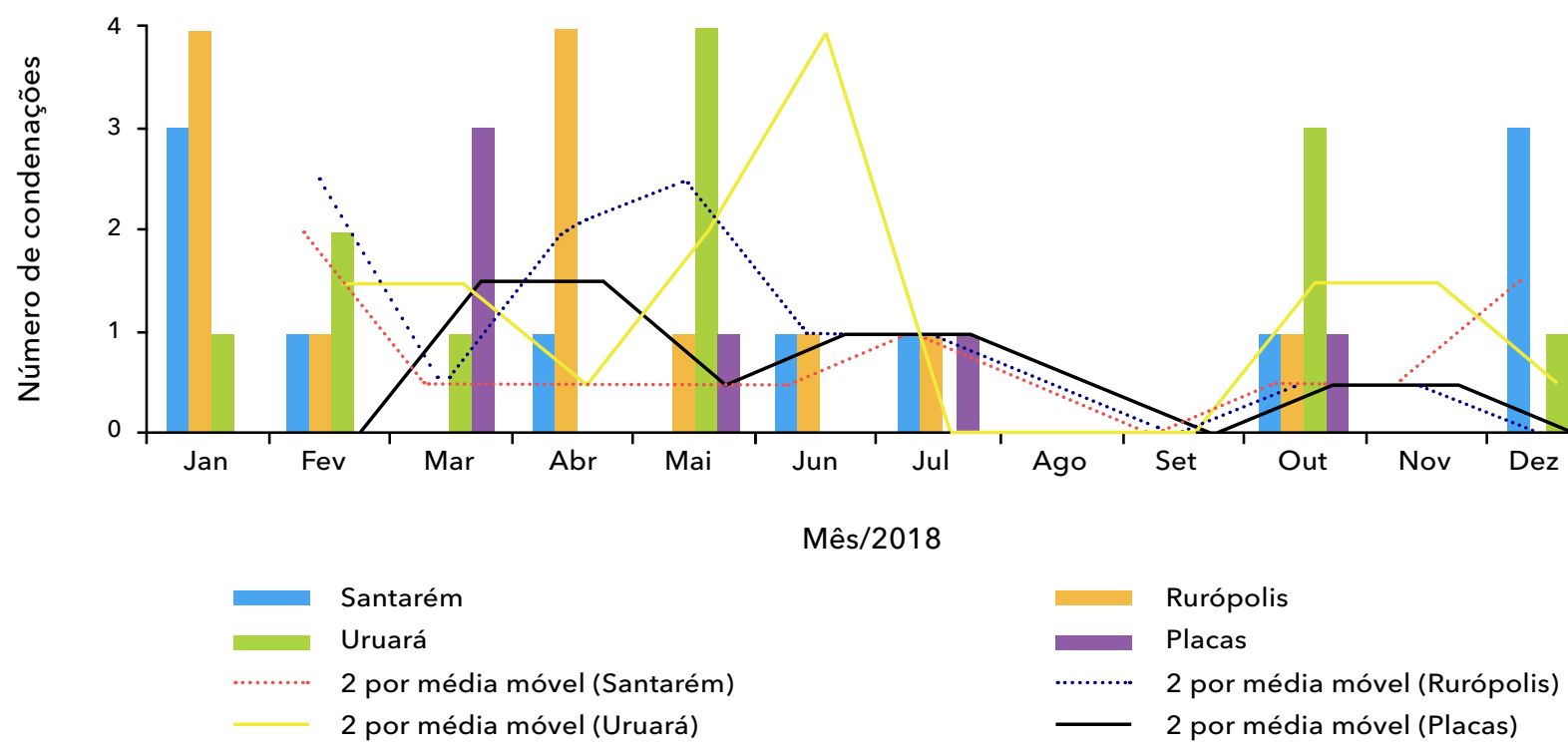

Figura 1 - Relação de bovinos condenados por brucelose nos meses do ano de 2018 nas regiões do Baixo Amazonas e Sudoeste Paraense, com linha de tendência entre os municípios. 
Em Rurópolis, os meses de janeiro e abril apresentaram maior número de casos quando comparados aos demais meses do ano, no entanto, não foram diagnosticados casos em março, agosto, setembro, novembro e dezembro. No município de Placas, o mês de março apresentou o maior número de casos, seguido de maio, julho e outubro, não havendo registros nos demais meses (Figura 1).

Ao analisar a média móvel nos municípios de Uruará, Rurópolis e Santarém, observou-se maior ocorrência de casos no primeiro semestre, seguida de redução no segundo semestre. No entanto, este estudo não pôde determinar o fator responsável pela elevação da prevalência de brucelose no primeiro semestre em comparação ao segundo do ano de 2018. Em Placas, identificou-se que os casos ocorreram a partir do mês de março, quando houve o maior número de condenações, com posterior redução de casos à medida em que se aproximou o segundo semestre do ano. Ademais, os municípios Uruará, Rurópolis e Placas fornecem animais para o abate a partir do mês de dezembro, em virtude do bom escore corporal que estes apresentem (Figura 1).

\section{Conclusão}

O maior número de condenações por brucelose ocorreu em bovinos pertencentes ao município de Rurópolis e com idade superior a 7 anos. Observou-se maior índice de condenações no primeiro semestre do ano de 2018, sendo Santarém o município que apresentou maior quantidade de machos condenados, no entanto as fêmeas foram predominantes entre os casos de condenações por municípios.

\section{Referências}

Acha PN, Szyfres B. Zoonosis y enfermedades transmissibles com unes al hombre y a losanimales. Washington, DF: OPS; 2001. p. 28-56.

Baptista F, Leite RC, Haddad JA, Almeida KS, Nardi CPP. Prevalence an drisk factors for brucellosis in Tocantins and Brazilian national program to fight this disease. Rev Patol Trop. 2012;41(3):285-94.

Bataier Neto M, Santos WRM, Inforzato GR, Tozzetti DS, Pereira REP. Brucelose Bovina. Rev Cient Eletr Med Vet. 2009;7(12):1-6.

Beer J. Doenças infecciosas em animais domésticos: doenças produzidas por bactérias e fungos e intoxicações. v. 2. São Paulo: Roca; 1988. 380 p.

Brasil. Ministério da Agricultura, Pecuária e Abastecimento. Instrução Normativa n. 10, de 3 de março de 2017. Estabelece o Regulamento Técnico do Programa Nacional de Controle e Erradicação da Brucelose e da Tuberculose Animal - PNCEBT. DOU; 20 jun 2017a.

Brasil. Ministério da Agricultura, Pecuária e Abastecimento. Decreto $n^{\circ}$ 9.013, de 29 de março de 2017. Dispõe sobre o regulamento da inspeção industrial e sanitária de produtos de origem animal. Art. 163. DOU; 30 mar 2017b.

Celestino ALO, Petry AC, Castro BG. Anticorpos antiBrucella abortus em bovinos abatidos em Sinop, Mato Grosso. Rev Acad Cien Anim. 2016;14(2):169-76.

Elandt-Johnson RC. Definitionof rates: some remarks on their use and misuse. Am J Epidemiol. 1975;102(4): 267-71.

Freitas FAD, Cavalcanti ML, Marques ASC, Mesquita FPN, Amorim AS, Leite Al. Prevalência de brucelose em bovinos na região do Potengi, estado do Rio Grande do Norte. Acta Vet Bras. 2008;2(4):118-22.

Freitas JA, Oliveira JP. Pesquisa de infecção brucélica em bovídeos abatidos portadores de bursite. Arq Inst Biol. $2005 ; 72(4): 427-33$.

Lauar NM. Brucelose. Boletim técnico, 169. Campinas: CATI; $1983.13 \mathrm{p}$.

Leal Filho JM, Bottene IFN, Monteiro LARC, Pellegrin AO, Gonçalves VSP, Ferreira F, et al. Control of bovine brucellosis from 1998 to 2009 in the state of Mato Grosso do Sul, Brazil. Semina Cienc Agrar. 2016;37(5 Supl 2):3467-78. 
Monteiro LARC, Pellegrin AO, Ishikawa MM, Osório ALAR. Investigação epidemiológica da brucelose bovina em um estrato do Estado de Mato Grosso do Sul. Pesq Vet Bras. 2006;26(4):217-22.

Oliveira LF, Dorneles EMS, Mota ALAA, Gonçalves VSP, Ferreira Neto JS, Ferreira F, et al. Seroprevalence and risk factors for bovine brucellosis in Minas Gerais State, Brazil. Semina Cienc Agrar. 2016;37(5 Supl 2):3449- 66.

Pereira MF, Cirne LGA, Neves KAL, Claudiano GS, Costa AS, Castro E KF, et al. Condenações de bovídeos abatidos sob inspeção municipal em Santarém - PA. Agroecos. 2009;9(2):78-90.

Poester F, Figueiredo VCF, Lôbo JR, Gonçalves VSP, Lage $A P$, Roxo $E$, et al. Estudos de prevalência da brucelose bovina no âmbito do Programa Nacional de Controle e Erradicação de Brucelose e Tuberculose: Introdução. Arq Bras Med Vet Zootec. 2009;61(Supl 1):1-5.

Poester FP, Samartino LE, Santos RL. Pathogenes is and pathobiology of brucellosis in livestock. Rev Sci Tech. 2013;32(1):105-15.
Poletto R, Kreutz LC, Gonzales JC, Barcellos LJG. Prevalência de tuberculose, brucelose e infecções víricas em bovinos leiteiros do município de Passo Fundo, RS. Cienc Rural. 2004;34(2):595-8.

Rocha WV, Gonçalves VSP, Coelho CGNFL, Brito WMED, Dias RA, Delphino MKVC, et al. Situação epidemiológica da brucelose bovina no Estado de Goiás. Arq Bras Med Vet Zootec. 2009;61(Suppl 1):27-34.

Sabedot MA, Boetcher AV, Pozza MSS, Busanello M, Mangoni J. Ocorrência de tuberculose e brucelose em rebanhos da região sudoeste do Paraná. Rev Cient Eletr Med Vet. 2009;7(12):1-9.

Zinsstag J, Dean A, Baljinnyam Z, et al. Brucellosis surveillance and control: a case for One Health. In: Zinsstag J, Schelling E, Waltner-Toews D, Whittaker M, Tanner M (E.E.). One Health: the theory and practice of integrated health approaches. Wallingford: CABI; 2015. p. 153-62. 